Тюрин Игорь Юрьевич, канд. техн. наук, доцент кафедры «Техническое обеспечение АПК», Саратовский государственный аграрный университет имени Н.И. Вавилова. Россия.

Левченко Галина Викторовна, канд. техн. наук, доцент кафедры «Механика и инженерная графика», Саратовский государственный аграрный университет имени Н.И. Вавилова. Россия.

410060, г. Саратов, ул. Советская, 60. Тел.: (8452) 74-96-23.

Ключевые слова: агрегат; почва; обработка; выравнивание почвы; рабочий орган.

\title{
MODIFICATION OF THE PLANTER FOR SOWING SMALL-SEEDED CROPS
}

Golubev Vyacheslav Viktorovich, Candidate of Technical Sciences, Associate Professor of the chair "Technological and Transport Machines and Complexes", Tver State Agricultural Academy. Russia.

Nikiforov Maxim Viktorovich, Senior Teacher of the chair "Technological and Transport Machines and Complexes", Tver State Agricultural Academy. Russia.

Firsov Anton Sergeevich, Senior Teacher of the chair "Technological and Transport Machines and Complexes", Tver State Agricultural Academy. Russia.

Tyurin Igor Yurievich, Candidate of Technical Sciences, Associate Professor of the chair "Technical Support of Agroindustrial Complex", Saratov State Agrarian University named after N.I. Vavilov. Russia.
Levchenko Galina Viktorovna, Candidate of Technical Sciences, Associate Professor of the chair "Mechanics and Engineering Graphics", Saratov State Agrarian University named after N. I. Vavilov. Russia.

Keywords: aggregate; soil; treatment; soil leveling; working organ.

The agrotechnical requirements of presowing soil cultivation have been analyzed, shortcomings in the seed plot have been revealed, in particular parameters of soil leveling and depth of seeding. A grain seeder for sowing grass seeds has been modernized, flax.

DOI

удк 628.29

\section{АНАЛИЗ СОСТОЯНИЯ СИСТЕМ ВОДООТВЕДЕНИЯ НА ТЕРРИТОРИИ РОССИЙСКОЙ ФЕДЕРАЦИИ}

ЕСИН Александр Иванович, Саратовский государственный аграрный университет имени Н.И. Вавилова

ГОРБАЧЕВА Мария Петровна, Саратовский государственный аграрный университет имени Н.И. Вавилова

В статье проведен анализ современного состояния очистных сооружений в составе систем водоотведения на территории Российской Федерации. Сформулированы мероприятия, направленные на повышение эффективности работы очистных сооружений.

Введение. Рассматривая систему водоотведения как комплекс инженерных сооружений, назначением которых является обеспечение сбора и удаления сточных вод за пределы населенного пункта, их очистку и обеззараживание, следует отметить, что наиболее дорогостоящими являются очистные сооружения. Согласно переписи населения 2015 г., 81 \% городского населения страны имеют центральную канализацию, что характеризует достаточно высокий уровень благоустройства, однако для сельской местности этот показатель снижен до 35,4 \%. На территории страны работает около 9 тыс. систем канализации, протяженность которых составляет около 75 тыс. км. Следует отметить, что 29 городов и около 300 поселков городского типа не имеют централизованных систем канализации.

Методика исследований. Проведен анализ статистический данных по состоянию очистных сооружений на территории РФ, которые представлены в официальных источниках литературы, за последние 5 лет.

Более 80 \% очистных сооружений в составе канализационной системы либо не функционирует, либо не обеспечивает необходимое качество очистки. Основная доля принадлежит сооружениям по биологической очистке, которые в настоящее время находятся в неудовлетворительном техническом состоянии, 


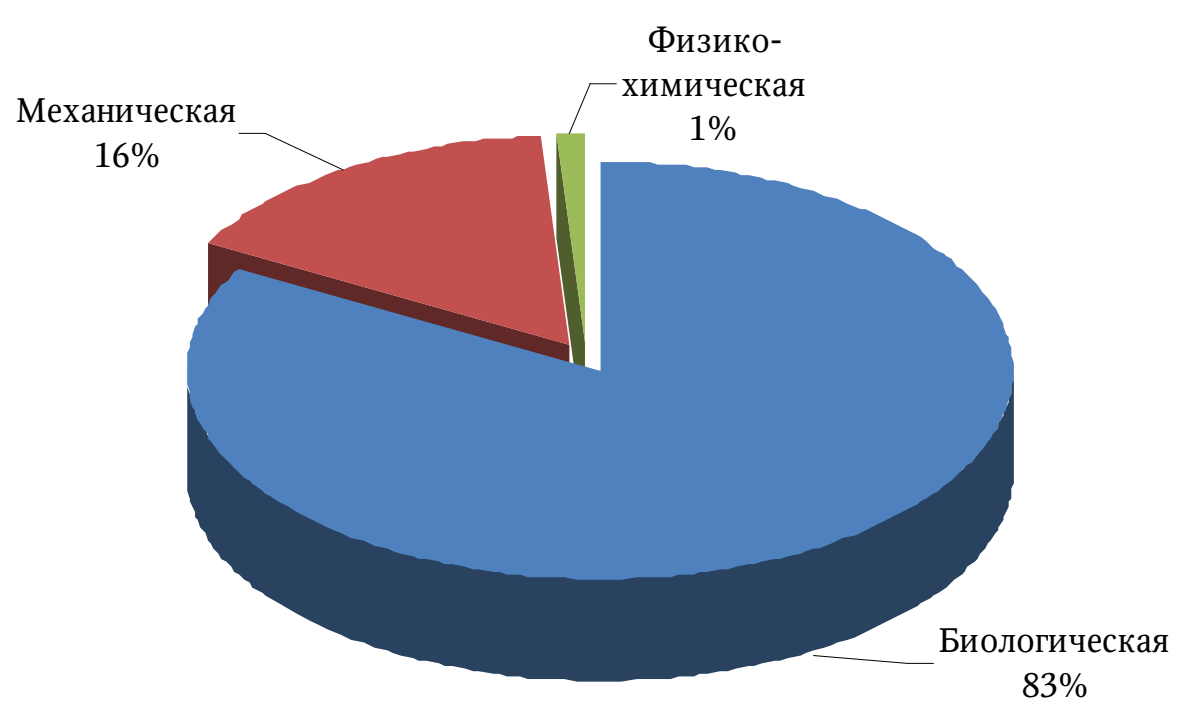

Рис. 1. Распределение сбрасываемых сточных вод по видам очитски

так как основная масса очистных сооружений Российской Федерации была построена в 1950-1970-х гг.

Согласно данным за 2017 г., 41,8 \% от всей длины уличной канализации страны нуждается в полной замене, что составляет 32,8 тыс. км.

В зависимости от типа системы водоотведения на территории России основная часть сточных вод проходит полную биологическую очистку, а остальная механическую и физико-химическую очистку. Распределение общего объема стоков, которые после различных видов очистки сбрасываются в водные объекты, представлено на рис. 1. В ряде случаев возникает несоответствие технологии очистки состоянию подаваемых сточных вод. Данный факт характеризует неэффективное использование очистных сооружений [1].

Традиционные технологии очистки на очистных станциях - коагулирование, фильтрация на песчаных фильтрах, хлорирование - хорошо справляются с такими традиционными загрязнениями, как взвешанные вещества, природная органика, бактерии. Но они неэффективны против современных химических средств: косметики, моющих средств, нефтепродуктов. Так, например, в 2017 г. в водоемы России было сброшено 2112,14 т нефти и нефтепродуктов. Количество наиболее опасных химических соединений, сброшенных в водоемы за последние 5 лет, представлено на рис. 2.

Активный хлор, который предназначен обеззараживать воду, вступает с этими

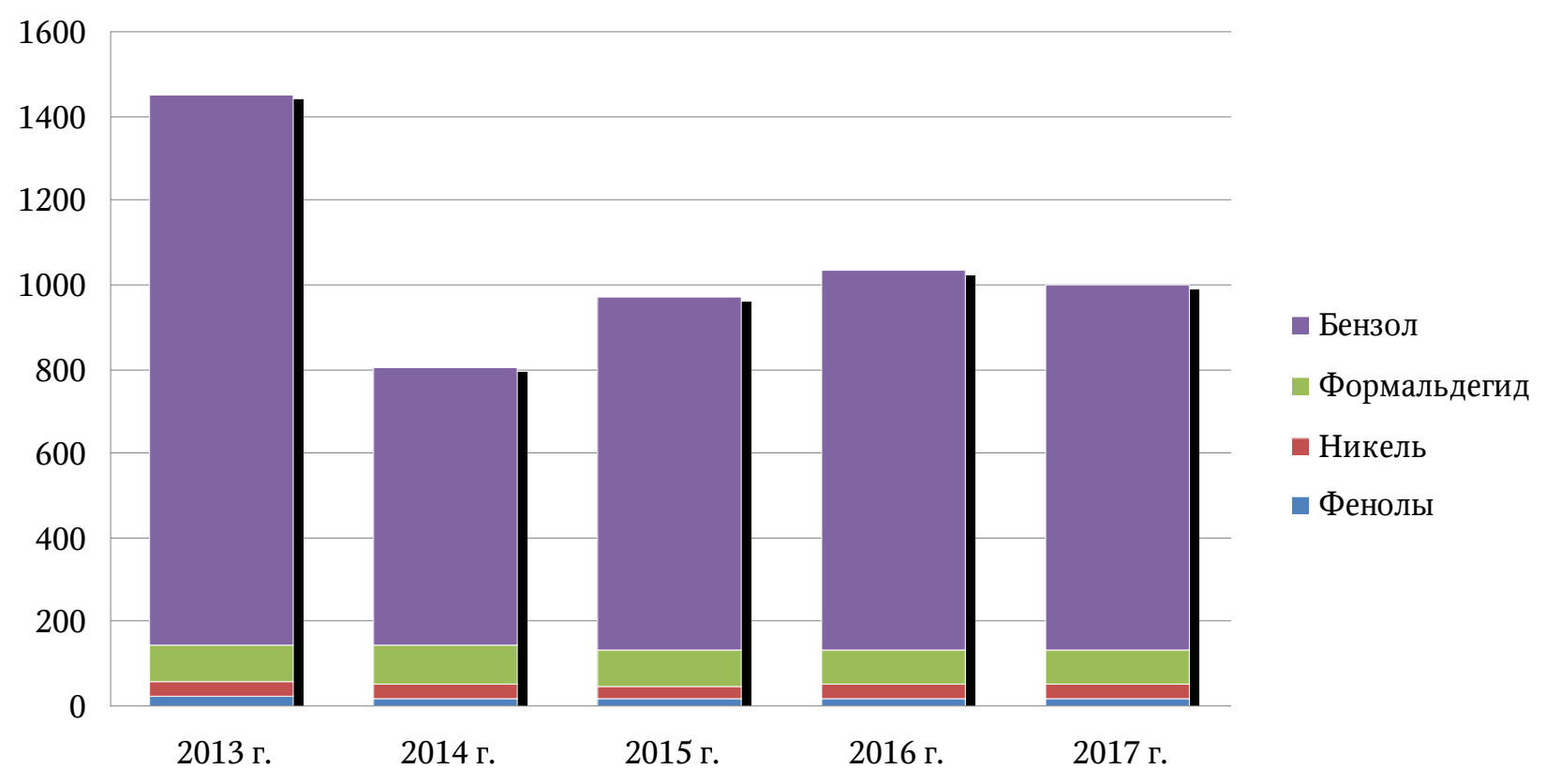

Рис. 2. Объем сброса вредных веществ неорганического происхождения 
химическими веществами в реакции, в результате чего формируются хлорорганические соединения, которые опасны для здоровья даже в минимальных концентрациях.

Аэротенки на очистных сооружениях, задача которых состоит в очистке от органических загрязнений, также неэффективны при очистке от современных химических загрязнений. Кроме того, наличие вредных веществ неорганического происхождения в сточной воде негативно воздействует на бактерии активного ила.

Согласно статистическим данным, на территории РФ в последние годы прослеживается тенденция снижения общего объема сточных вод, требующих очистки (рис. 3). Данный факт возник в связи с экономической нестабильностью в стране и прекращением работы или снижением мощностей производства многих промышленных предприятий, однако одной из проблем для очистных сооружений является неравномерность поступления стоков в течение суток, что создает дополнительную нагрузку.

Эффективность работы очистных сооружений можно характеризовать долей нормативно очищенных сточных вод по отношению к общему объему воды, которая проходила очистку. В целом для территории России данный показатель свидетельствует о перегруженности или отсутствии очистных сооружений в ряде федеральных округов. В большинстве субъектов России для очист- ных сооружений характерна низкая эффективность работы, и это напрямую связано с их неудовлетворительным техническим состоянием [1].

Следует отметить, что поступление сточных вод в водные объекты без очистки в водоемы России в 2017 г. составляло 2,9 км³, т.е. 6,8 \% от общего объема сточных вод. Динамика сбрасываемых сточных вод за последние 5 лет, которые не прошли нормативную очистку, показана на рис. 4.

Для большинства субъектов Российской Федерации основным источником загрязнения поверхностных водоемов является жилищнокоммунальное хозяйство. В настоящее время на территории страны работает около 9 тыс. систем канализации.

Более 60 \% сточных вод, сбрасываемых без надлежащей очистки, относится к 9 субъектам Российской Федерации: Москва и Московская область, Санкт-Петербург, Краснодарский край, Челябинская область, Свердловская область, Самарская область, Иркутская область, Кемеровская область, Республика Татарстан (рис. 5) [1].

Данный факт крайне негативно влияет на экологическое состояние водных объектов. Органическое загрязнение приводит к ускорению процессов, происходящих с потреблением растворенного кислорода, что в конечном итоге приводит к дефициту кислорода. Преобразование азота в восстановленные формы в анаэробных условиях в свою очередь обусловливает повышение концентра-

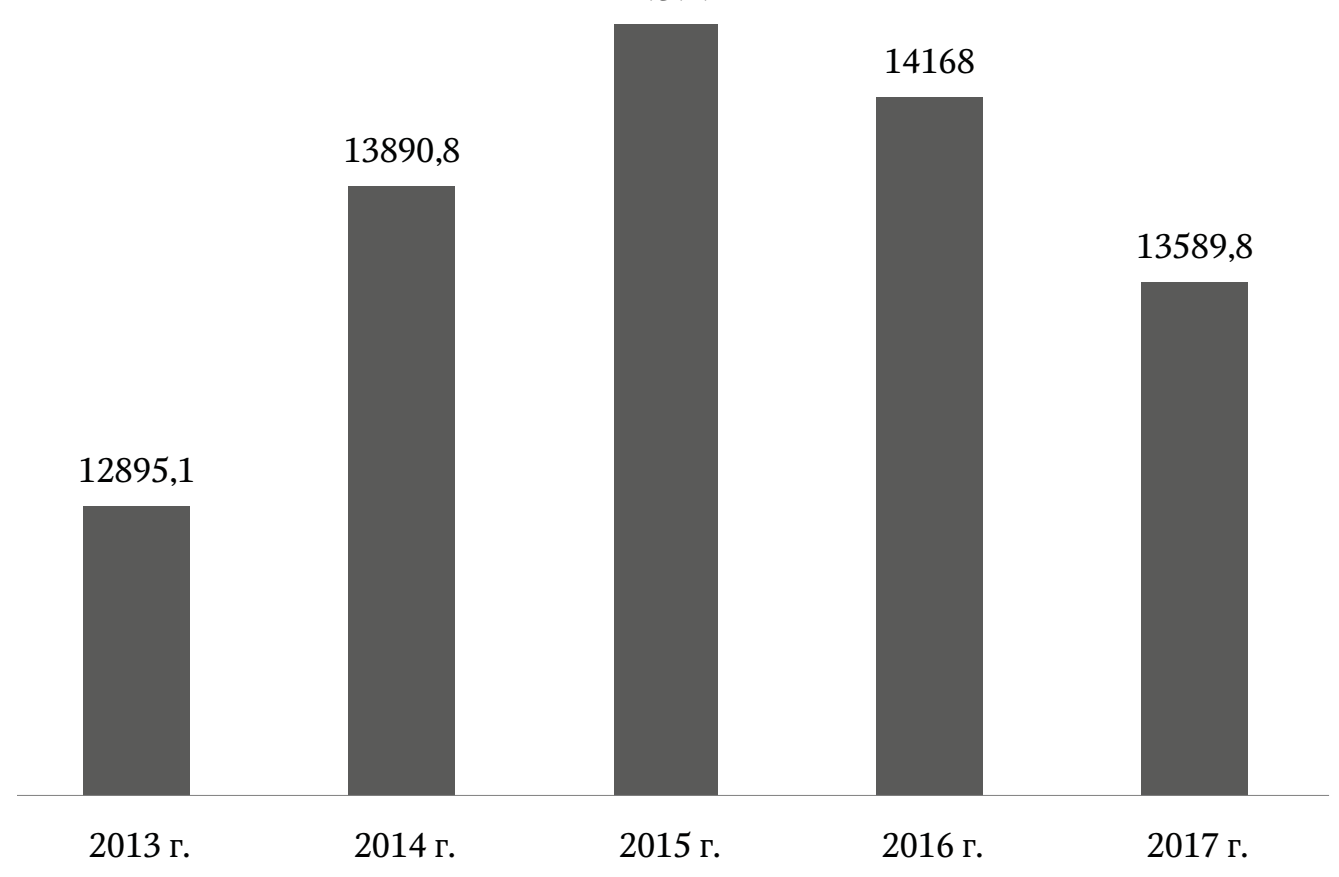




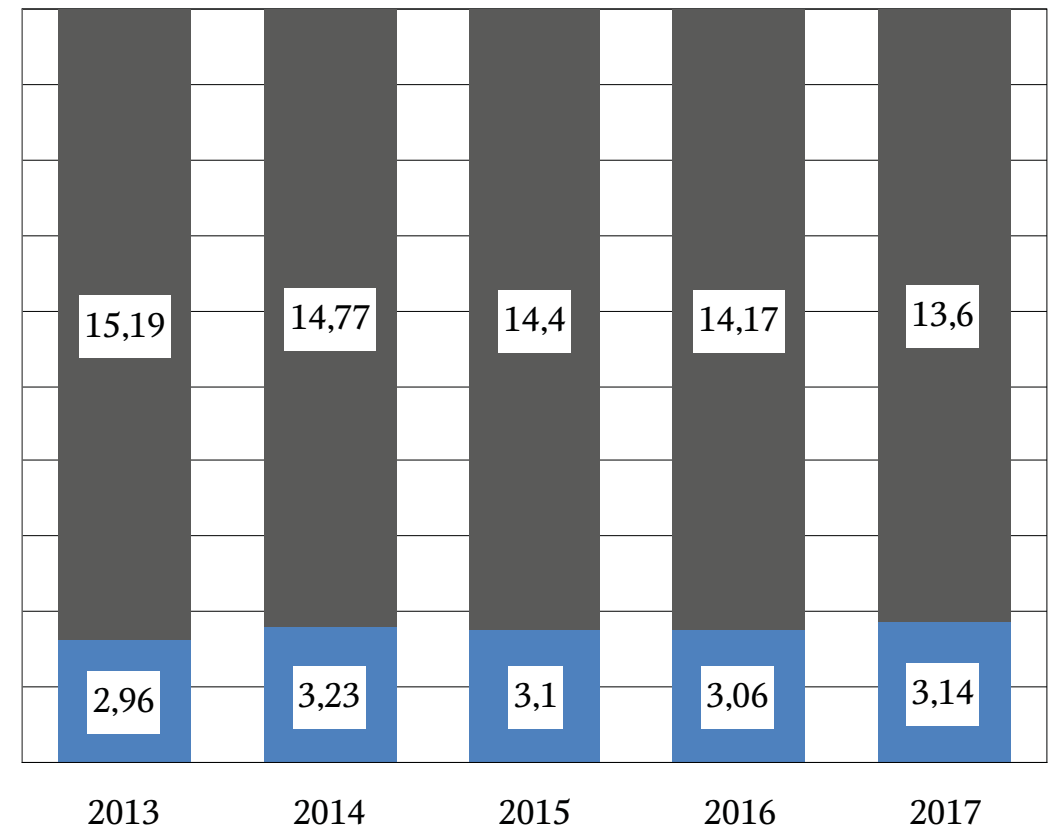

- Недостаточно очищенные сточные воды

— Срос без очистки

Рис. 4. Динамика сбрасываемых загрязненных сточных вод в РФ, км ${ }^{3} / 2 о д$

ции аммонийного азота, который является токсичным для водных сообществ в концентрациях, превышающих допустимый уровень в зависимости от температуры, минерализации и показателя $\mathrm{pH}$ воды.

На территории России практически все водоемы подвергаются воздействию вредных антропогенных загрязнений, особенно такие реки, как Волга, Дон, Томь, Уфа, Северная Двина, Урал, а также реки Дальнего Востока и Сибири.

На сегодняшний день состояние пресноводных водоемов Российской Федерации оценивается на 164 водных объектах. Лишь 35 \% водоемов являются относительно чистыми, 56 водоемов - слабозагрязненными.
Из 72 водных объектов, которые отнесены к наиболее загрязненным по классу качества воды, 24 \% водоемов являются экстремально грязными, $33 \%$ - очень грязными и $43 \%$ грязными [1].

Данная ситуация является результатом неэффективной очистки сточных вод, вследствие чего в водоемы попадает огромное количество загрязняющих веществ. На рис. 6 приведены данные некоторых веществ органического происхождения, сброшенных в водоемы России в 2017 г.

Другой проблемой является устаревшая система ливневой канализации на территории России. Во многих городах трубы, дождеприемные решетки, коллекторы и на-

Самарская обл.

399,13

Кемеровская обл.

Иркутская обл. 524,49

Свердловская обл.

586,18

Челябинская обл.

691,3

Краснодарский край

765,6

г. Москва

844,57

г. Санкт-Петербург

1033,06

Московская обл. 


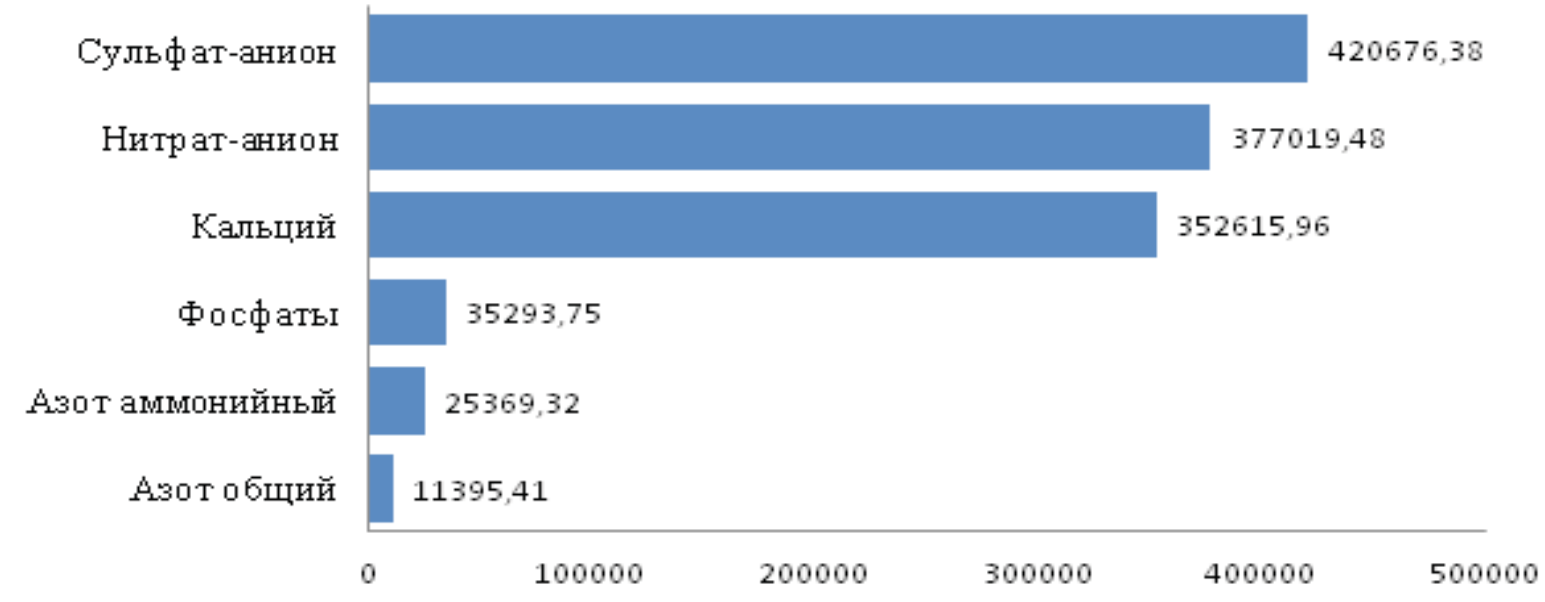

Рис. 6. Объем сброса некоторых загрязняющих веществ в водные объекты Российской Федерации в 2017 г., $\mathrm{m} /$ год

сосные станции давно выработали свой ресурс и сильно изношены. К тому же многие из систем проектировались еще в середине $\mathrm{XX}$ в., и их мощности не хватает при возросших объемах стоков. Пропускную способность «ливневки», которую строили еще в 1960-70-е гг., нужно увеличить минимум на $20 \%$, чтобы она справилась с количеством осадков.

Данная ситуация приводит к тому, что после выпадения осадков потоки воды, захватывая мусор и все загрязняющие вещества, которые находятся на поверхности автомобильных дорог и улиц населенного пункта, напрямую, минуя очистные сооружения, попадают в водоемы.

Результаты исследований. Обобщая вышеизложенное, среди причин неудовлетворительной работы очистных сооружений можно выделить: частое несоответствие технологии очистки составу поступающих сточных вод;

высокий уровень износа существующих очистных сооружений;

отсутствие необходимого объема средств для реконструкции и модернизации очистных сооружений.

Данный факт является причиной процесса эвтрофирования многих водоемов на территории Российской Федерации, которое обусловлено прежде всего избыточным поступлением в них соединений азота и фосфора. Возбудителями «цветения» воды в водоемах являются сине-зеленые водоросли [2-4].

Анализ показывает, что водоемы с малыми скоростями течения воды (рис. 7) и наличием органических веществ являются наиболее благоприятными ландшафтами для обильного развития водорослей $[5,7]$.

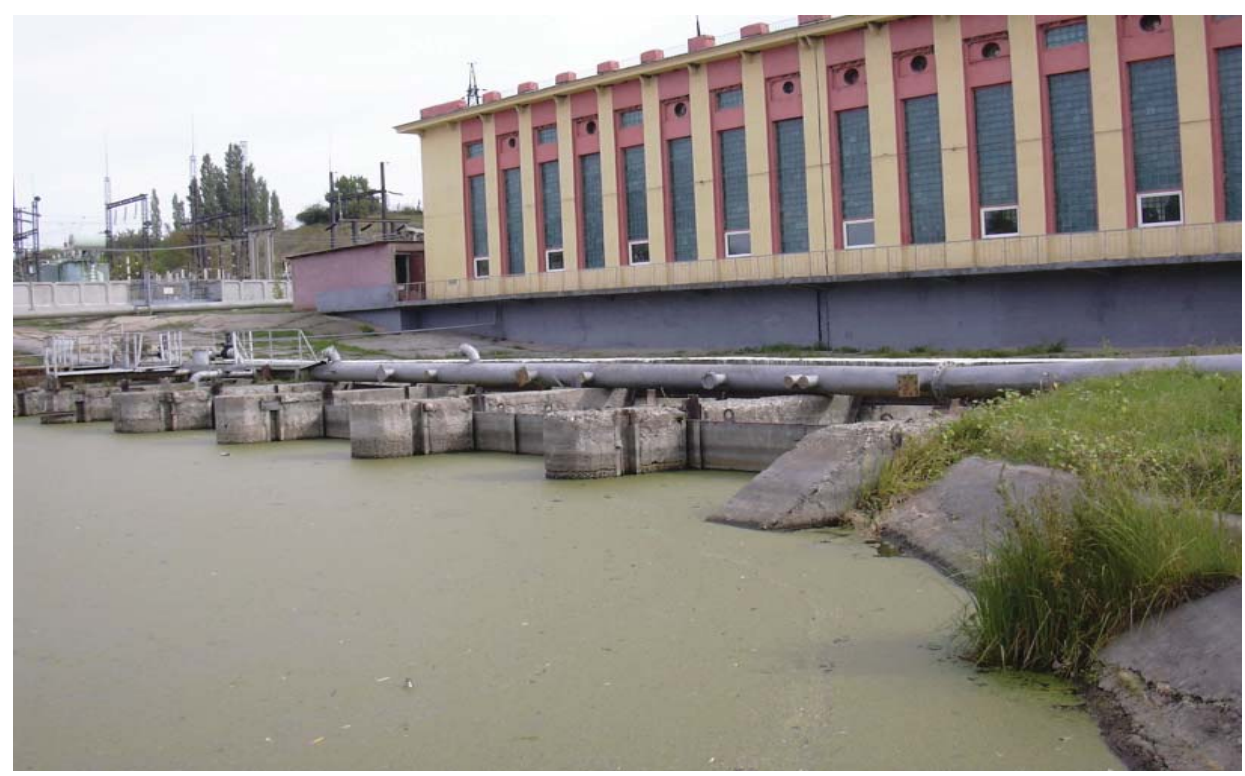


Одним из существенных факторов, определяющих загрязнения водных объектов на территории РФ, является неспособность обеспечить достаточный уровень очистки всего объема сточных вод [6].

Объем нормативно очищенных сточных вод в 2017 г. составлял всего 4,35 \% от общего объема сточных вод, что характеризует низкую эффективность работы существующих очистных сооружений, обусловленную ухудшением их технического состояния, а в ряде населенных пунктов - отсутствием очистных сооружений вообще. Во многих субъектах РФ сбрасываемые сточные воды не соответствуют категории нормативноочищенных сточных вод и сбрасываются в водоемы загрязненными. Особенно данный факт характерен для небольших населенных пунктов, где сброс в водоемы происходит без какой-либо очистки.

Заключение. Одним из важнейших направлений улучшения водоохраной обстановки на территории Российской Федерации являются мероприятия, направленные на повышение эффективности работы очистных сооружений:

соблюдение норм ПДС при сбросе очищенных сточных вод в водные объекты;

использование наиболее современных разработок при строительстве новых очистных сооружений и индивидуальный подход к каждому объекту строительства при составлении схемы очистки сточных вод;

ремонт и реконструкция действующих очистных сооружений и для более эффективного их использования, обеспечение регулирования канализационного стока, что создаст равномерную нагрузку на очистные сооружения.

\section{СПИСОК ЛИТЕРАТУРЫ}

1. Государственный доклад «О состоянии и об охране окружающей среды Российской Федерации в 2017 году». - М., 2017.
2. Горбачева М.П. Основные факторы, вызывающие «цветение» воды в водоемах // Системные исследования природно-техногенных комплексов Нижнего Поволжья: сб. науч. трудов. - Саратов, 2007. - C. 23-26.

3. Горбачева М.П. Проблема интенсивного зарастания водоемов // Материалы Междунар. науч.практ. конф. В 6 ч. - М., 2014. - С. 14-15.

4. Есин А.И., Горбачева М.П. Удаление из оросительной воды мусора растительного происхождения // Совершенствование методов гидравлических расчетов водопропускных и очистных сооружений. - Саратов, 2008. - Т. 1 (34). C. 64-66.

5. Есин А.И., Горбачева М.П. К вопросу о распространении примесей органического происхождения в мелиоративных каналах // Аграрный научный журнал. - 2014. - № 9. - С. 35-38.

6. Есин А.И., Горбачева М.П. Проблема очистки водоемов от мусора растительного происхождения с дальнейшей утилизацией // Вестник учебно-методического объединения по образованию в области природообустройства и водопользования. - 2015. - № 7(7). С. $141-144$.

7. Миркина Е.Н., Горбачева М.П. Новые технологии улучшения качества воды // Культурно-историческое наследие строительства: вчера, сегодня, завтра: материалы Междунар. науч.-практ. конф. - М.; Саратов, 2014. - С. 80-83.

Есин Александр Иванович, $\partial-p$ техн. наук, профессор кафедры «Техносферная безопасность $и$ транспортно-технологические машиныл, Саратовский государственный аграрный университет имени Н.И. Вавилова. Россия.

Горбачева Мария Петровна, канд. техн. наук, доцент кафедры «Инженерные изыскания, природообустройство и водопользование», Саратовский государственный аграрный университет имени Н.И. Вавилова. Россия.

410056, г. Саратов, ул. Советская, 60.

Тел.: (8452) 74-96-53.

Ключевые слова: очистные сооружения; сточные воды; виды очистки воды; водные объекты; загрязняющие вещества; эвтрофирование водоемов.

\section{ANALYSIS OF THE STATE OF THE SEWERAGE SYSTEMS ON THE TERRITORY OF THE RUSSIAN FEDERATION}

Esin Aleksandr Ivanovich, Doctor of Technical Sciences, Professor of the chair "Technosphere Safety and Transport and Technological Machines", Saratov State Agrarian University named after N.I. Vavilov. Russia.

Gorbacheva Maria Petrovna, Candidate of Technical Sciences, Associate Professor of the chair "Engineering Surveying, Environmental Engineering and Water Consumption", Saratov State Agrarian University named after N.I. Vavilov. Russia.
Keywords: treatment facilities; wastewater; types of water treatment; water body; pollutant; eutrophication of water bodies.

The article analyzes the current state of treatment facilities as part of wastewater disposal systems in the Russian Federation. Poor technical condition of treatment facilities is the main cause of pollution of water bodies. The measures aimed at improving the efficiency of treatment facilities are formulated. 